encouraged to be assiduous in their measures to prevent mosquito bites while abroad, especially if there is an epidemic of dengue at their destination.

1 World Health Organisation. Dengue haemorrhagic fever: diagnosis, treatmen and control. Geneva: WHO, 1986

Risdall RJ, McKenna RW, Neshit ME, et al. Virus-associated hemophagocytic syndrome Cancer 1979:44:993-1002.
3 Sabin AB. Research on dengue during world war II. Am f Trop . Med Hyg 1952;1:30-50

4 Halstead SB, Udomsakdi S, Singharaj P, Nisalak A. Dengue and chikunguns: virus infection in man in Thailand, 1962-1964. III. Clinical, epidemiologic, and virologic observations on disease in non-indigenous white persons. Am 9 Trop Med Hyg 1969:18:984-96.

Halstead SB. Pathogenesis of dengue: challenges to molecular biology. Science 1988:239:476-81.

Accepted 8 January 1991$)$

\section{Influence of undergraduate teaching on medical students' attitudes to rectal examination}

\author{
T W Hennigan, P J Franks, D B Hocken, \\ T G Allen-Mersh
}

\section{Department of Surgery, Charing Cross and Westminster Medical School, London W6 8RF T W Hennigan, FRCS, lecturer P J Franks, PHD, research fellow \\ D B Hocken, FRCs, lecturer T G Allen-Mersh, FRCS,} consultant

Correspondence to: Mr Hennigan.

BMf 1991;302:829 attitudes to rectal examination.

\section{Subjects, methods, and results}

The confidence of general practitioners in their ability to diagnose a condition based on rectal examination and a belief that they have been thoroughly taught rectal examination at medical school appreciably influence general practitioners' frequency of rectal examination.' We investigated medical students' experience of rectal examination during training and assessed whether teaching at medical school influences

We sent a questionnaire to 119 final year medical students in one medical school. General surgical subspecialty interest (breast, gastrointestinal, vascular, urological, or general) of the four firms that each student had been attached to and whether attachments were in teaching or non-teaching hospitals were recorded. Students were asked about the number of rectal examinations they had performed for specific anorectal conditions and in total; formal teaching of rectal examination, seniority of teacher, when they were taught, and whether they were taught on anaesthetised patients; reasons for omitting routine rectal examination; and confidence in their diagnosis of specific anorectal conditions based on rectal examination. The end points were categorised and analysed using Kendall's $\tau \mathrm{C}$ test. ${ }^{2}$ Overall score for confidence in diagnosis was determined by summing the values (yes $=1$, no $=0$ ) for the five conditions (range 0 to 5 ). Confidence score was dichotomised around the median (0 to 3,4 to 5 ).

We received replies from 114 medical students $(96 \%$ response rate). The median category for total number of rectal examinations performed was 11 to $30 ; 23 \mathrm{had}$ done fewer than 10 examinations and 19 had never felt a rectal cancer. The table shows the main results.

Only 32 students routinely performed a rectal examination when examining patients. Factors that deterred students from rectal examination were being told not to do so by medical staff ( 35 students), embarrassment (14), refusal of patients (10), and lack of chaperon (three). Students who had done more than the median number of rectal examinations were significantly more confident about diagnosing rectal cancer $(\tau \mathrm{C}=0 \cdot 174, \mathrm{p}=0 \cdot 013)$, benign prostatic hyperplasia ( $\tau \mathrm{C}=0.150, \mathrm{p}=0.006$ ), prostate cancer $(\tau$ $\mathrm{C}=0 \cdot 142, \mathrm{p}=0 \cdot 028)$, and anal fistula $(\tau \mathrm{C}=0 \cdot 157)$, $\mathrm{p}=0.030$ ) than were those who had done fewer than the median. Confidence was significantly greater about diagnosing benign prostatic hyperplasia $(\tau \mathrm{C}=0 \cdot 108$, $\mathrm{p}=0.026)$, prostatic carcinoma $(\tau \mathrm{C}=0 \cdot 185, \mathrm{p}=0.004)$, rectal carcinoma $(\tau \mathrm{C}=0.135, \mathrm{p}=0.032)$, and anal
Factors influencing students' confidence of diagnosis based on rectal examination

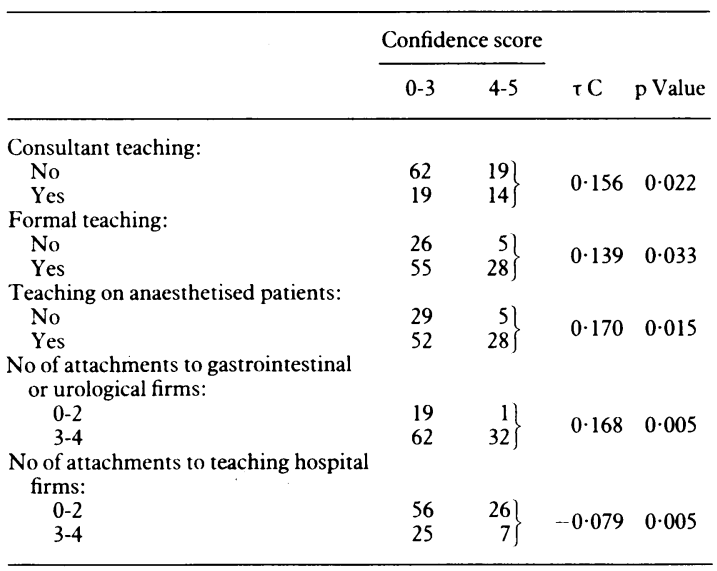

fistula ( $\tau \mathrm{C}=0 \cdot 143, \mathrm{p}=0.031)$ among students who had done more than two non-teaching hospital attachments than it was among those who had done fewer.

\section{Comment}

Formal teaching (especially by a consultant) encouraged the view among medical and nursing staff that students are expected to do rectal examinations. Only 33 students had been formally taught rectal examination by a consultant. More confident students did more rectal examinations. Easily deterred students would become more confident if clinicians encouraged rectal examination. The outpatient clinic is ideal for one to one teaching and minimises patient and student embarrassment. Attachment to a firm with a subspecialty interest that regularly used rectal examination in diagnosis and treatment increased confidence.

Possible reasons for attachment to a non-teaching hospital increasing confidence include the presence of fewer students and the heavier general surgical emergency workload, which provides a greater variety of anorectal conditions. Students in non-teaching hospitals did not receive more formal tuition than those in teaching hospitals.

Though the factors affecting confidence identified might seem obvious, there is scope for improvement. A fifth of students had done fewer than 10 rectal examinations and $54 \%$ had been deterred from routine rectal examination. Frequency of rectal examination after graduation is influenced by attitudes acquired during training. ${ }^{\prime}$ Consultant teaching and emphasis on the importance of rectal examination by students will increase confidence and produce doctors who are more willing to perform rectal examination.

We thank the medical students for completing the questionnaires.

1 Hennigan TW, Franks PJ, Hocken DB, Allen-Mersh TG. Rectal examination in general practice. $B M \mathcal{F} 1990 ; 301: 478-80$

2 SPSS Incorporated. Statistical package for the social sciences $-X$ : user's guide. 2nd ed. New York: McGraw Hill, 1986.

(Accepted 21 fanuary 1991) 